\title{
Modifiable worker risk factors contributing to workplace absence: A stakeholder-centred best-evidence synthesis of systematic reviews
}

\author{
Shannon Wagner ${ }^{\mathrm{a}, *}$, Marc White $^{\mathrm{b}, \mathrm{h}}$, IzabelaSchultz ${ }^{\mathrm{c}}$, Eleanor Murray ${ }^{\mathrm{d}}$, Susan M. Bradley, \\ Vernita $\mathrm{Hsu}^{\mathrm{f}}$, Lisa McGuire ${ }^{\mathrm{g}}$ and Werner Schulz ${ }^{\mathrm{e}}$ \\ ${ }^{a}$ School of Health Sciences, University of Northern British Columbia, Prince George, BC, Canada \\ ${ }^{\mathrm{b}}$ Department of Family Practice, University of British Columbia, Vancouver, BC, Canada \\ ${ }^{c}$ Department of Educational and Counseling Psychology and Special Education, University of British Columbia, \\ Vancouver, BC, Canada \\ ${ }^{\mathrm{d}}$ Epidemiologist, Boston, MA, USA \\ e Information Resource Librarian, Consultant, Vancouver, BC, Canada \\ ${ }^{\mathrm{f}}$ BC Construction Safety Alliance, New Westminster, BC, Canada \\ ${ }^{g}$ The FIOSA-MIOSA Safety Alliance of BC, Chilliwack, BC, Canada \\ ${ }^{\mathrm{h}}$ Canadian Institute for the Relief of Pain and Disability, Vancouver, BC, Canada
}

Received 23 January 2013

Accepted 6 May 2013

\begin{abstract}
.
BACKGROUND: A challenge facing stakeholders is the identification and translation of relevant high quality research to inform policy and practice. This study engaged academic and community stakeholders in conducting a best evidence-synthesis to identify modifiable risk and protective worker factors across health conditions impacting work-related absence.

OBJECTIVES: To identify modifiable worker disability risk and protective factors across common health conditions impacting work-related absence.

METHODS: We searched Medline, Embase, CINHAL, The Cochrane Library, PsycINFO, BusinessSourceComplete, and ABI/ Inform from 2000 to 2011. Quantitative, qualitative, or mixed methods systematic reviews of work-focused population were considered for inclusion. Two or more reviewers independently reviewed articles for inclusion and methodological screening. RESULTS: The search strategy, expert input and grey literature identified 2,467 unique records. One hundred and forty-two full text articles underwent comprehensive review. Twenty-four systematic reviews met eligibility criteria. Modifiable worker factors found to have consistent evidence across two or more health conditions included emotional distress, negative enduring psychology/personality factors, negative health and disability perception, decreased physical activity, lack of family support, poor general health, increased functional disability, increased pain, increased fatigue and lack of motivation to return to work.

CONCLUSIONS: Systematic reviews are limited by availability of high quality studies, lack of consistency of methodological screening and reporting, and variability of outcome measures used.
\end{abstract}

Keywords: Disability prevention, risk and protective factors, occupational health

\footnotetext{
* Corresponding author: Shannon Wagner, School of Health Sciences, University of Northern British Columbia, 3333 University
}

Way, Prince George, BC V2N 4Z9, Canada. Tel.: +1 250960 6320; Fax: +1 250 9605744; E-mail: Shannon.Wagner@unbc.ca. 


\section{Introduction}

Workplace absence, prolonged disability, and associated costs of injuries and chronic disease, pose a significant burden to workers, employers, and society [13]. Given the serious negative consequences related to workplace absence and prolonged duration of disability, there has been a growing body of primary studies and systematic reviews investigating risk and protective factors contributing to work absence and prolonged disability.

\subsection{Academic community partnership}

The present synthesis was created by an academic community partnership (ACP). This partnership involved researchers from different fields and disciplines at three British Columbia (BC) universities, and three community partners, two occupational health and safety organizations and a not-for-profit health and welfare trust that administers group health and welfare benefits for over 100,000 employees in the health care and social service sector in BC.

From discussions during the planning phase of this study, it was clear that workplace practitioners were motivated to learn from current research, but found the literature difficult to understand and interpret into practical solutions, lacked access to relevant research articles, and required expert assistance in critical appraisal of the literature [4]. To address these concerns proactively, we engaged workplace stakeholders fully in the research synthesis process so that primary knowledge users participated in identifying the research question, selecting the search terms, refining the exclusion and inclusion criteria, providing oversight of the data abstraction processes, and participating in categorization of the findings and preparation of the final report.

Utilizing an iterative problem identification and clarification process, stakeholders reported that many small and medium size employers do not have a disability coordinator, or the capacity to consider appropriate preventive action to address risk or protective factors at the level of a specific chronic disease or injury; rather, they expressed interested in learning what factors might be more generalizable across injuries and chronic health conditions. These deliberations by the ACP led to a decision to conduct a stakeholdercentered best evidence synthesis of systematic reviews on disability risk and protective factors associated with work-related and chronic disease health conditions impacting work-related absences and disability duration.
The present article reports the methods and findings of the synthesis specifically, related to modifiable risk and protective worker factors. A previous article presented results on modifiable risk and protective workplace factors [5].

\section{Methods}

\subsection{Partnership process}

Stakeholder and academic researchers participated in an iterative systematic process involving face-toface meetings, videoconferencing, review, reflective input regarding meeting minutes, and workflows and surveys, to define the purpose of the systematic review and participate as full research partners throughout the synthesis process. Full contribution included participation in the identification of the research question, refining inclusion-exclusion criteria, creation of the template for abstracting findings, validation of abstraction, categorization of factors and final report preparation for their constituents. We conducted a series of pilot searchers providing examples of literature found; we then circulated the interim results, and sought input on keywords to identify pertinent and stakeholderrelevant systematic reviews. This initial process allowed for effective review of search terms used in relevant studies and led to refinement of the research question, followed by development of stakeholdercentered appropriate inclusion/exclusion criteria that informed the final search strategy. MeSH terms (structure language for Medline) and keywords across other databases were reviewed by one or more external librarians with expertise in health sciences, social sciences, and business databases, during the pilot search process.

\subsection{Inclusion/exclusion criteria}

Our inclusion criteria were systematic reviews that included adults (age 15+) and a work-focused population (i.e. working or attempting to secure work); all systematic reviews that employed qualitative metaanalyses, quantitative meta-analyses, and non-metaanalytic systematic reviews of both qualitative and quantitative literature were considered for inclusion. Additionally, to be considered for inclusion, systematic reviews were required to address work absence related to workers presenting with personal illness, health condition, or illness as an outcome, including physical 
Table 1

Methodological quality review

\begin{tabular}{|c|c|c|}
\hline Question & Answer choice & Score \\
\hline \multicolumn{3}{|l|}{ Common criteria for both qualitative and quantitative methodological review } \\
\hline Did the authors have a clearly focused question? & $\begin{array}{l}\text { Yes } \\
\text { No }\end{array}$ & $\begin{array}{l}1 \\
0\end{array}$ \\
\hline Were inclusion/exclusion criteria used? & $\begin{array}{l}\text { Yes } \\
\text { No } \\
\text { Not specified }\end{array}$ & $\begin{array}{l}1 \\
0 \\
0\end{array}$ \\
\hline $\begin{array}{l}\text { Did the authors describe a search strategy that was comprehensive and } \\
\text { reproducible? }\end{array}$ & $\begin{array}{l}\text { Yes } \\
\text { No } \\
\text { Not specified }\end{array}$ & $\begin{array}{l}1 \\
0 \\
0\end{array}$ \\
\hline Please click the search strategies used & (selected/unselected) & $\begin{array}{l}\text { a. Five or more databases: } 2 \\
\text { b. Two to four databases: } 1 \\
\text { c. One database: } 0\end{array}$ \\
\hline Did search strategy cover an adequate number of years? $(10+$ years $)$ & $\begin{array}{l}\text { Yes } \\
\text { No }\end{array}$ & $\begin{array}{l}1 \\
0\end{array}$ \\
\hline Does the data support the author's interpretation? & $\begin{array}{l}\text { Yes, mostly } \\
\text { No }\end{array}$ & $\begin{array}{l}1 \\
0\end{array}$ \\
\hline Are there any concerns related to COI? & $\begin{array}{l}\text { Yes } \\
\text { No }\end{array}$ & $\begin{array}{l}0 \\
1\end{array}$ \\
\hline $\begin{array}{l}\text { Specific criteria quantitative methodological quality } \\
\text { Did the review assess the methodological quality of the primary studies? }\end{array}$ & $\begin{array}{l}\text { Yes } \\
\text { No }\end{array}$ & $\begin{array}{l}1 \\
0\end{array}$ \\
\hline What methods did the authors use to combine or compare results across studies? & $\begin{array}{l}\text { Meta-analyses } \\
\text { Descriptive }+ \text { quality weight } \\
\text { Descriptive no weight } \\
\text { Other }\end{array}$ & $\begin{array}{l}2 \\
2 \\
1 \\
0\end{array}$ \\
\hline $\begin{array}{l}\text { How strong was the level of evidence supporting the strongest conclusions of } \\
\text { the study? }\end{array}$ & $\begin{array}{l}\text { Level } 1 \text { (RCT) } \\
\text { Level } 2 \text { (non-random) } \\
\text { Level } 3 \text { (uncontrolled) } \\
\text { Unclear }\end{array}$ & $\begin{array}{l}2 \\
1 \\
0 \\
0 \\
\text { Total score possible: } 13\end{array}$ \\
\hline $\begin{array}{l}\text { Specific criteria qualitative and mixed methodological quality } \\
\text { Did the review assess the methodological quality of the primary studies? } \\
\text { (minimum of 4) } \\
\square \text { suitability of methodology /paradigm to the research question } \\
\square \text { sampling (selection of participants/settings/documentation) } \\
\square \text { clear description of context, data collection, and data analysis } \\
\square \text { rigor (audit trail, some coding by } 2 \text { or more coders, deviant case analysis, } \\
\text { respondent validation) } \\
\square \text { triangulation } \\
\square \text { reflexivity (researcher and research process) } \\
\square \text { relevance (credibility, consistency, applicability, transferability) }\end{array}$ & $\begin{array}{l}\text { Yes } \\
\text { No }\end{array}$ & $\begin{array}{l}1 \\
0\end{array}$ \\
\hline $\begin{array}{l}\text { Was this methodological quality review incorporated in the data analysis } \\
\text { (weighting of higher quality studies)? }\end{array}$ & $\begin{array}{l}\text { Descriptive }+ \text { quality weight } \\
\text { Descriptive no weight } \\
\text { Other }\end{array}$ & $\begin{array}{l}2 \\
1 \\
0\end{array}$ \\
\hline $\begin{array}{l}\text { How strong was the level of evidence supporting the strongest conclusions of } \\
\text { the study? }\end{array}$ & $\begin{array}{l}\text { Level } 1 \text { (RCT) } \\
\text { Level } 2 \text { (non-random) } \\
\text { Level } 3 \text { (uncontrolled) } \\
\text { Unclear }\end{array}$ & $\begin{array}{l}2 \\
1 \\
0 \\
0 \\
\text { Total score possible: } 13\end{array}$ \\
\hline
\end{tabular}

and/or mental conditions, and also were required to discuss predictive factors of work absence. Our exclusion criteria included reviews where the primary illness was a mental and/or extremely rare condition, a severe physical condition, or reviews that focused on a spe- cific specialized occupation, such as police, firefighters or air traffic controllers. Also excluded were systematic reviews which focused only on interventions, with no identification or discussion of risk or protective factors. 


\subsection{Search strategies}

All search strategies were originally written by an information specialist and were reviewed by one or more of her peers. Search results were uploaded to RefWorks and then exported to Excel. Removal of duplication was completed manually. Other sources of records included scoping searches, expert input, grey literature searches of health-evidence.ca, Rehab, National Rehabilitation Information Center (NARIC), and Institute of Work and Health (IWH). Hand-searching of the proceedings of a relevant conference (found in the EMBASE search) was also completed. After the initial search results were reviewed, the MEDLINE search strategy was reviewed and modified by a second information resource officer to simplify logic and ensure congruency with search terms. A copy of the MEDLINE search strategy is available online.

\subsection{Evaluation of quality and relevance}

Methodological quality of eligible studies was evaluated using principles and procedures congruent with recommendations discussed in The PRISMA Statement and the Institute of Medicine's Standards for Systematic Reviews [6]. This included (i) use of multiple information resource people, researchers and stakeholders in the development of search strategy, (ii) pilot-testing search strategy to identify stakeholderrelevance of articles, search terms used in relevant retrieved articles, (iii) validation procedures to assess comprehensiveness of Medline search strategy, (iv) assessing retrieved titles and abstracts for relevance, (v) selecting articles for more in-depth review, (vi) obtaining full text copies of these potentially eligible reviews, and assessing these reviews for relevance and quality (using independent assessment by at least two members of the review team), (vii) pilot testing abstraction process (for relevance and comprehensiveness) with stakeholders, and (viii) attention to production of final report relevant to stakeholders' needs and their organizational context.

The original methodological criteria were based on a quality assessment tool developed by researchers at McMaster University for Health-evidence.ca, a website supporting knowledge translation relevant to public health nursing. Researchers compared the original criteria with EBM Glasgow Checklist for Systematic Reviews, and assessed for congruency with AMSTAR methodological quality recommendations for critical appraisal of systematic reviews [7]. Methodological criteria were reviewed and refined by the ACP using a process of sharing (email distribution), discussion, reflection and consensus. Changes were made in scoring and standardizing questions across quantitative, qualitative and mixed methodological criteria (see Table 1).

The nature of the studies included in the present analysis was heterogeneous in nature and precluded the use of meta-analysis as a primary method of evaluation. Best-evidence synthesis was therefore chosen to be our main method of critical appraisal $[8,9]$. Bestevidence synthesis bases analysis on three aspect of evaluation: quality, quantity and consistency of available evidence [10].

Our results are reported based upon our teamdeveloped evaluation model (see Table 4) indicating the fit with the criteria for a given factor in relationship to the methodological quality of the review. Importantly, this framework was discussed with the stakeholder members and reflected team perceptions and understanding regarding categorization and ranking of evidence. Effect size and/or assessment of variance were not able to be calculated across reviews given the different outcome factors, types of studies and level of reporting. Therefore, the terms strong, moderate, and weak are not indicative of the degree to which a given factor will influence the workplace; rather, they reflect the quality, quantity and consistency of a respective factor.

The following additional questions/issues were asked of reviewers during the scientific review process: relevance to small employers, research strengths/weaknesses, implementation recommendations from authors, implementation recommendations from reviewers, and whether the systematic review met the inclusion/ exclusion criteria for this study. Preliminary data abstraction formats were prepared by the research associate, and were reviewed and modified by two researchers before circulation to ACP members. The forms for data abstraction consisted of Researcher Tables (Methods Results, Conclusions) and Stakeholder Synthesis Tables (Worker/Workplace Factors categorized by Modifiable and Non-Modifiable factors); the present article addresses modifiable worker factors only. After initial deliberations with stakeholders, it was decided to pilot the data abstraction forms by having the research associate abstract findings from 10 relevant articles. Copies of these articles were provided to the stakeholders; these team members were then asked to select two or more articles of interest that could be used to assess whether the abstraction forms had encompassed the required information or rather, had missed relevant findings. 


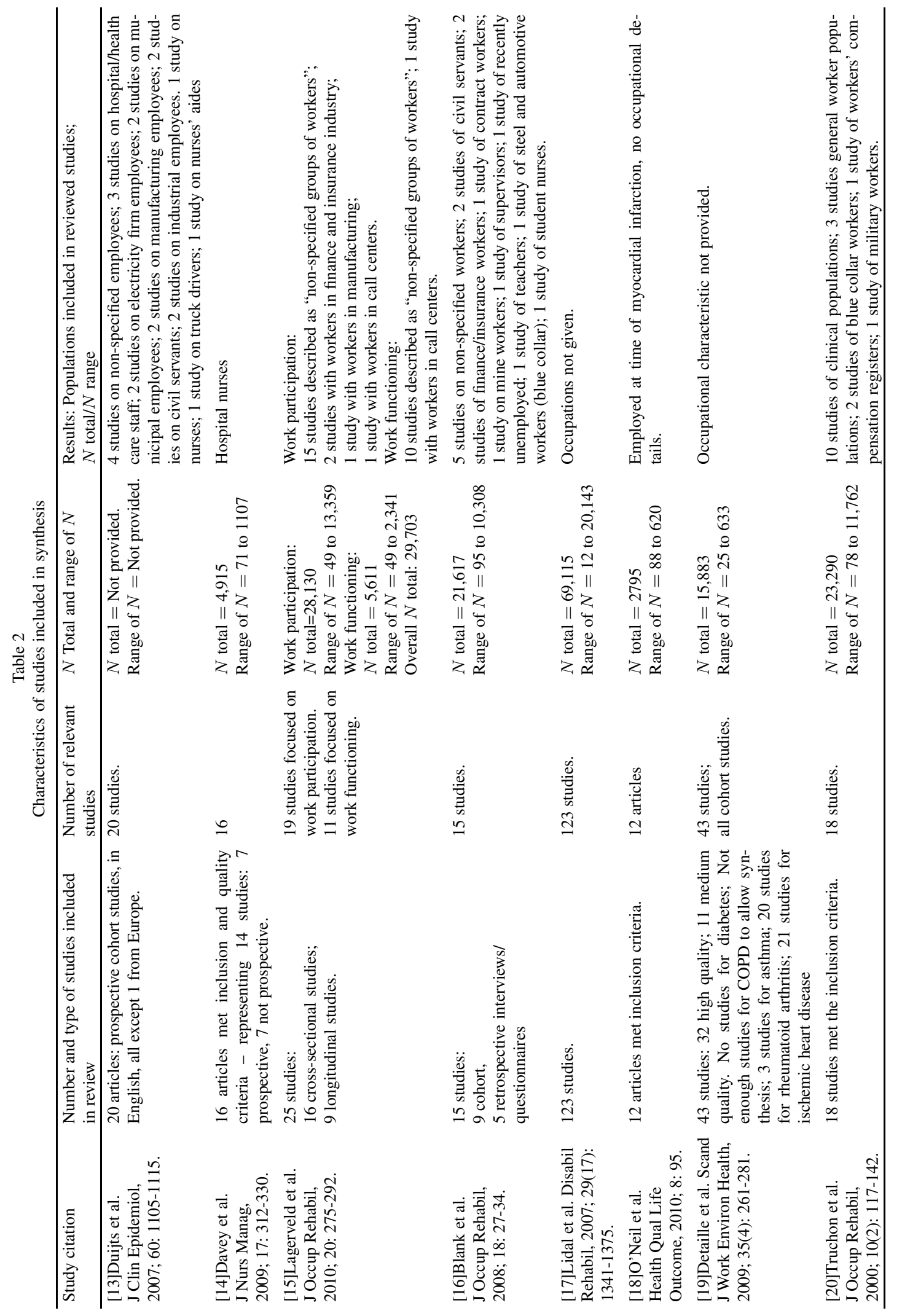




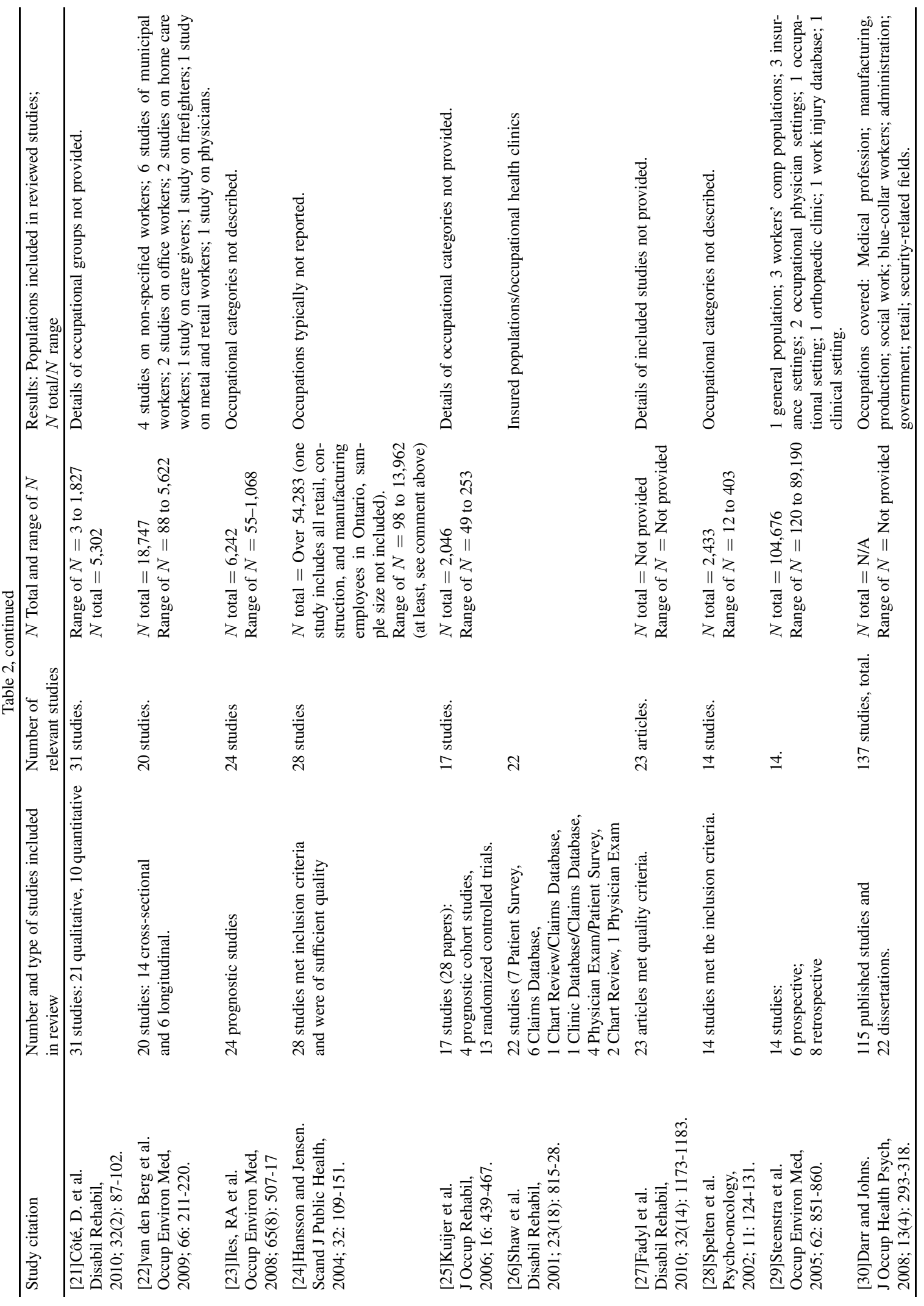




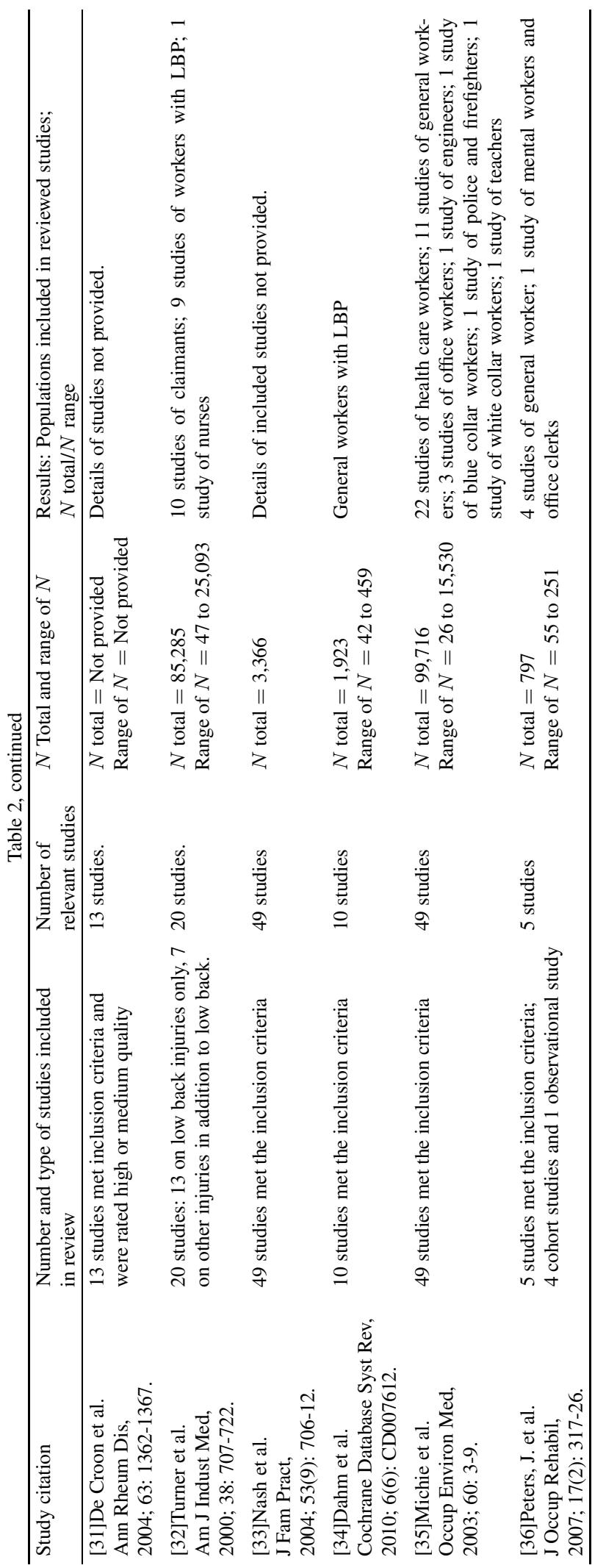




\subsection{Data abstraction}

A preliminary categorization of findings was developed following agreed upon concepts in the data abstraction forms. Once the abstraction tables were $90 \%$ complete, stakeholders were requested to appraise the initial categorization of factors. This review led to significant changes in the placement and naming of psychosocial and mental health factors. Following abstraction of the data into table format, the table data was interpreted into meaningful factor-level messages as presented below.

\section{Results}

\subsection{Search results}

There were 2,467 unique records identified and 142 full text articles were reviewed. Thirty-seven systematic reviews (quantitative, qualitative and mixed) met our eligibility criteria and methodological quality review for risk and protective factors associated with workplace absence. A subset of 24 systematic reviews from this overall search strategy addressed worker factors. As shown in Table 2, the 24 studies that met the synthesis inclusion criteria varied considerably in sample characteristics and size, data sources, and outcome measures.

\subsection{Validation of search strategy}

Records of database search strategies, de-duplication, other sources searched, and exclusions were recorded in VonVille's "Excel workbook to track systematic review search results" [11] and the final PRISMA flowchart [12] (Fig. 1) was generated using this workbook. Validation of the search strategy was performed by re-running the final MEDLINE search updated to August 31, 2011. Of the final included records (vide infra) for all factors (workplace, worker and societal factors), 36 had records in MEDLINE and 32 of these $(86 \%)$ were found using the final MEDLINE search.

\subsection{Methodological quality criteria}

A weighted scoring system was created to address quality of primary studies informing the systematic review as well as methods employed in combining and reporting results (see Table 3 ). The high- est methodological score possible was 13 with the range of scores being between 8 and 13 (these scores were subsequently translated into percentages). Fifteen studies were considered higher methodological quality systematic reviews (greater or equal to $85 \%$ ), three were considered medium quality reviews (between $75 \%-84 \%$ ), and six were considered lower quality reviews (between 50-74\%). All 24 systematic reviews were deemed to be of sufficient quality to contribute to evidence synthesis, with some of the lower quality scores resulting from limitations of the quality of primary studies informing the respective synthesis. To assess inter-rater reliability, methodological results were downloaded into MS Excel from Fluid Surveys, with responses recoded to reflect the scoring system employed. Kappa statistics were used to calculate the chance-adjusted between-reviewer agreement and disagreements per item and number of responses between sets of reviewers. This was calculated using an online kappa calculator (http://justusrandolph.net/kappa/). The overall inter-rater reliability score for the synthesis of the original 36 articles was 0.75 .

Using a best-evidence synthesis process it is important to note the terms strong, moderate, weak are not indicative of the predictive value of a given factor on workplace factors, as effect size or assessment of variance were not able to be calculated across reviews given different outcome factors, types of studies and level of reporting. Consequently, we used a teamdeveloped framework to indicate the consistency of a given factor in relationship to the methodological quality of the review (see Table 4). Importantly, this framework appeared to fit with the subjective feeling of the team and also provided a method of categorizing our evidence.

\subsection{Modifiable worker factors}

\subsubsection{Emotional distress and depression}

Five systematic reviews considered the impact of emotional distress on work disability. Duijts et al. [13] provided a high-quality review demonstrating strong evidence that increased level of burnout was associated with increased risk of sick leave of three days or less (adjusted OR $=1.28$ ) and of more than three days (adjusted OR $=2.34$ ) in workers with mild illness or injury. Davey et al. [14] also provided a highquality review and found that the presence of burnout and job stress were associated with increased risk of unplanned, short-term work absences in workers with 


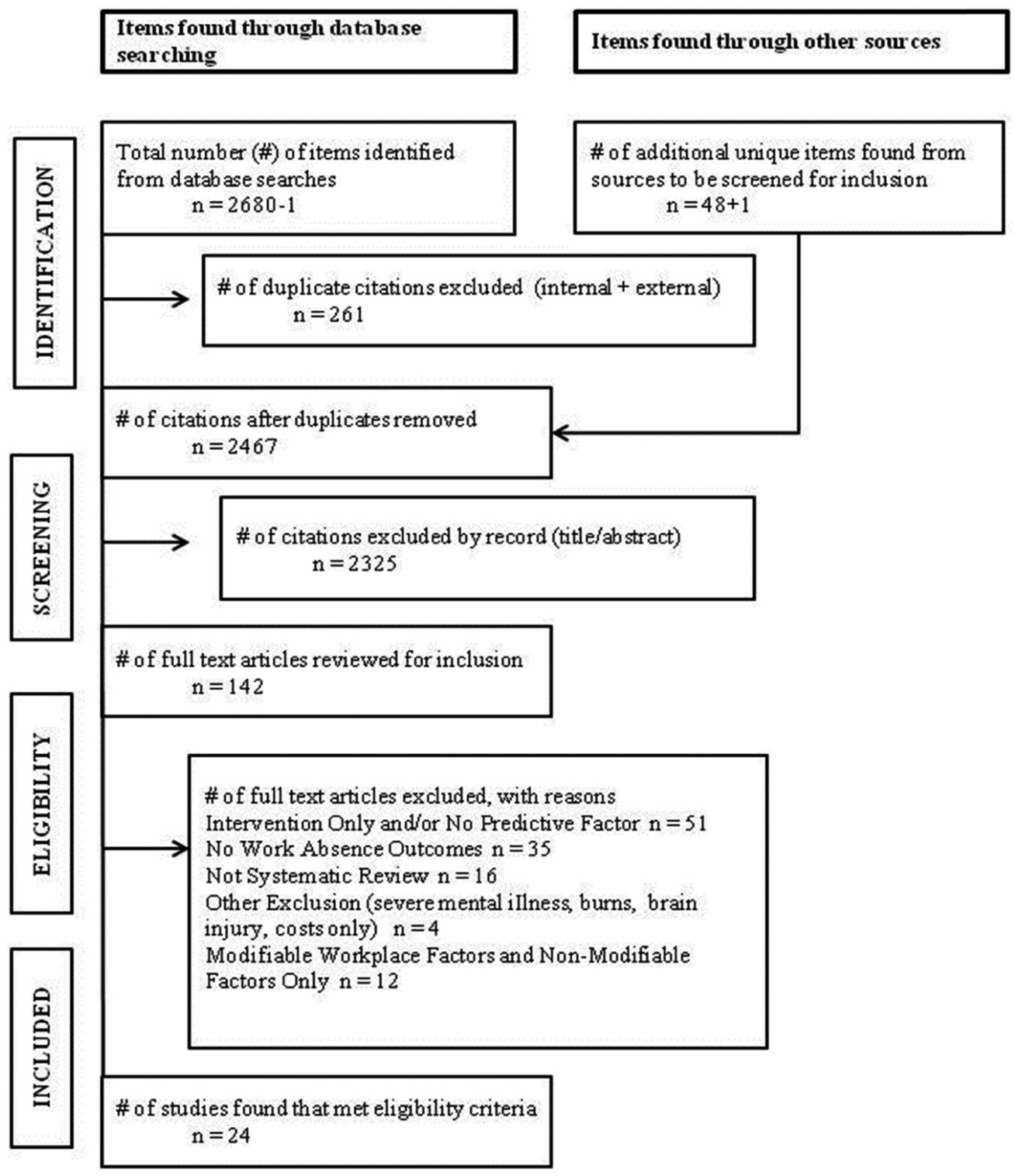

Fig. 1. Results of search strategy PRISMA chart.

psychosocial health concerns. The final high-quality study by Lagerveld et al. [15] found limited evidence that less clinical improvement of depressive symptoms predicted increased risk of poor work participation outcomes, including return to work and work status in workers. Blank et al. [16], in a moderate-quality review, reported that the presence of psychological disturbance resulting from work injury was associated with longer disability for workers with emotional distress arising from work injury. Finally, Lidal et al. [17], in a lower-quality review, reported that higher work stress was associated with the reduced rate of return to work in workers with spinal cord injury.

Two high-quality systematic reviews considered the impact of depression on work disability. Specifically, Lagerveld et al. [15] provided strong evidence that longer duration of depression increased risk of poor work participation outcomes, including return to work and work status, for individuals with depression. These authors also reported strong evidence that increased severity of depressive symptoms was associated with decreased return to work, and moderate evidence that increased severity was associated with as poor productivity and performance at work. O'Neil et al. [18] 
found similar outcomes and reported that more severe symptoms of depression were associated with decreased work resumption after myocardial infarction. There is strong evidence that emotional distress and increased depressive symptoms should be considered a predictor for work disability.

\subsubsection{Enduring psychological/personality factors}

Seven systematic reviews considered the impact of psychological/personality factors on work disability. A lack of studies regarding specific psychological/ personality factors required that this category include all aspects of this domain. Of the available seven systematic reviews, five of the reviews were considered of high quality. Detaille et al. [19] found moderate evidence that internal locus of control predicted reduced work disability in workers with cardiovascular conditions. Truchon et al. [20] found that negative attitudes about low back pain or other health problems and preoccupation with health were both associated with reduced return to work rates in individuals with low back pain. Duijts et al. [13] reported that excessive commitment was associated with increased risk of sick leave of more than three days (crude OR $=1.15$ ) in individuals with psychosocial health complaints. Cote and Coutu [21] found that changes in selfidentity due to illness or injury may result in poor fit with pre-injury job or with rehabilitation unit objectives for workers with persistent musculoskeletal pain, especially women. Lagerveld et al. [15] reported limited evidence that external locus of control predicted increased risk of poor work participation outcomes, including return to work and work status for individuals with depression. These authors also reported limited evidence that external locus of control and low selfesteem predicted increased risk of poor work functioning outcomes, including productivity or performance at work. Two lower quality reviews were also available. van den Berg et al. [22] found strong evidence that a lack of autonomy and low self-confidence both predicted poorer WAI scores (three out of four studies). The second lower-quality rated review by Lidal et al. [17] reported that higher levels of self-esteem and optimism were associated with increased return to work for individuals with spinal cord injury. There is strong evidence that enduring negative psychological/personality factors should be considered a predictor for work absence.

\subsubsection{Health and disability perceptions and expectations}

Ten systematic reviews considered the impact of health and disability perceptions on work disability. Similar to psychological/personality factors, specific factors within this category were often evaluated in only a single systematic review. The single exception was with respect to recovery expectations for which four high-quality and one lower-quality systematic reviews were available. As a result, all factors, except recovery expectations, were reviewed together. Of the ten included systematic reviews, eight were deemed to be of high quality. Detaille et al. [19] in one high-quality rated review found strong evidence that increased feelings of subjective vocational disability were associated with increased risk of work disability for individuals with cardiovascular conditions. Duijts et al. [13] in a second high-quality rated review reported that, for those with psychosocial health concerns, a high need for recovery was associated with increased sick leave of three days or more (adjusted $\mathrm{OR}=2.15$ ). Iles et al. [23] found moderate evidence that fear avoidance beliefs or behaviors were associated with decreased likelihood of return to work for those with non-chronic, non-specific low back pain. O'Neil et al. [18] found that unspecified perceptions of health and/or work were associated with reduced work resumption after myocardial infarction. Truchon et al. [20] found that lower subjective ability to work was associated with lack of return to work outcomes for individuals with low back pain. High-quality rated reviews demonstrating low or limited evidence included Hansson and Jensen [24] who found low evidence that higher perceived functional impairment predicted increased risk of sick leave greater than three months. Kuijer et al. [25] reported limited evidence that lower health transition score increased risk for sickness absence at follow-up and increased number of days of work for individuals with low back pain; these authors also found that increased musculoskeletal complaints increased number of days of work absence. Lagerveld et al. [15] reported limited evidence that hopelessness about future increased risk of poor work participation outcomes for workers with depression. A lower-quality rated review showing a similar relationship included Shaw et al. [26] who found strong evidence that higher perceived functional impairment predicted longer disability duration for individuals with low back pain ( 5 out of 7 studies). These authors also reported strong evidence that fear avoidance beliefs orbehaviours increased disability duration (5 out of 5 studies). Fadyl 


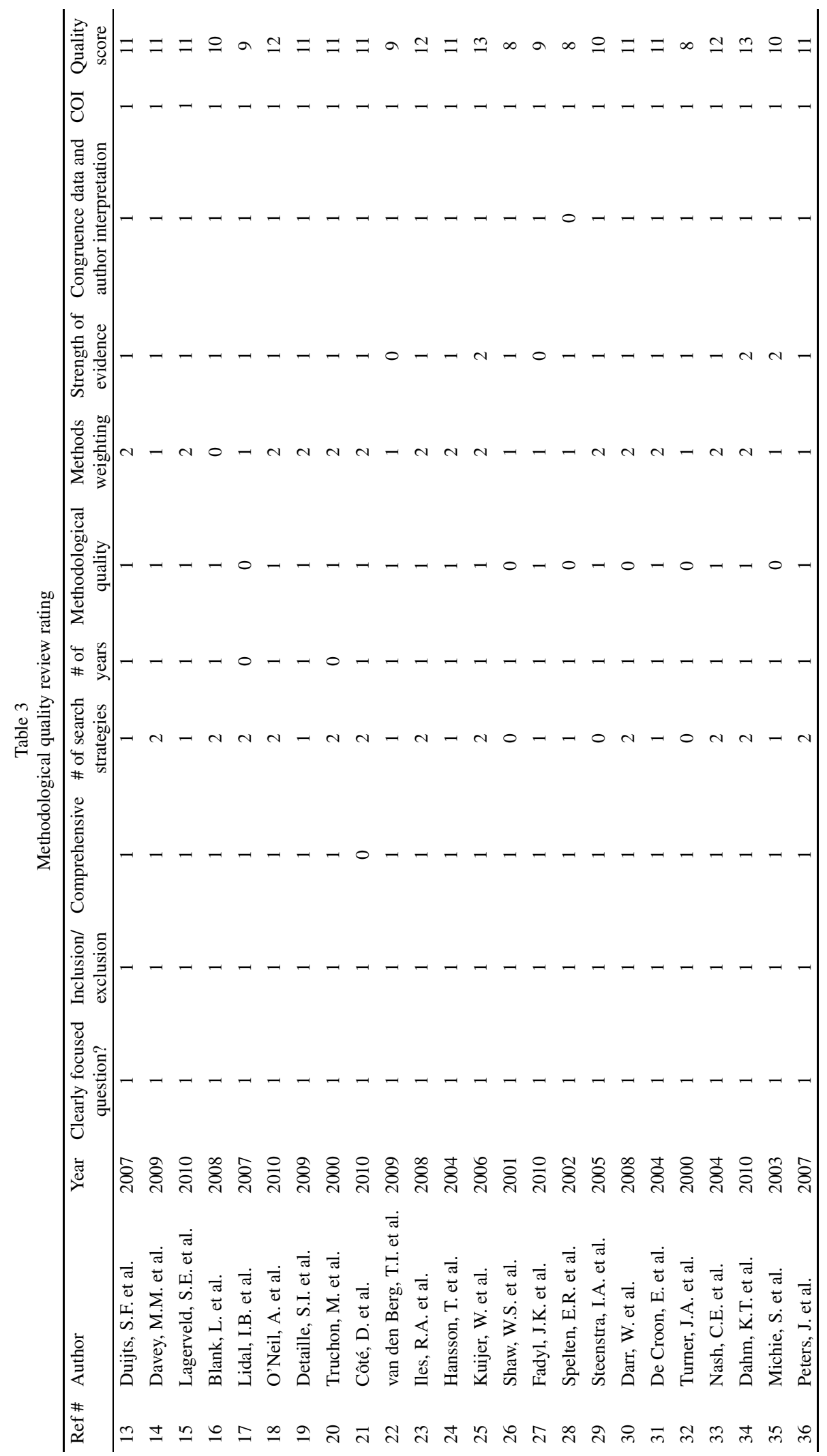


et al. [27] provided a low-quality rated review and reported that higher self-perceived rates of physical functioning were associated with increased work ability for individuals with work-related injury. There is strong evidence that negative health and disability perceptions should be considered a predictor of work disability.

Recovery expectations: Five systematic reviews considered the impact of recovery expectations on work disability. Four of these available systematic reviews were deemed to be of high quality. Iles et al. [23] provided strong evidence that positive recovery expectations increased likelihood of return to work in individuals with low back pain. Detaille et al. [19] found strong evidence that recovery expectations reduced risk of work disability in individuals with cardiovascular conditions. Kuijer et al. [25] provided consistent evidence of positive recovery expectations as associated with decreased risk of sickness absence at follow-up in workers with low back pain. O'Neil et al. [18] found consistent evidence $(>50 \%$ of studies that positive preoperative expectations increased likelihood of RTW with individuals with ischemic heart disease). Finally, Lidal et al. [17], in a low-quality rated review, looked at this relationship and found that positive expectations of reintegration in to work were associated with an increased return to work for individuals with spinal cord injury. There is strong evidence that negative recovery expectations should be considered a predictor of work disability.

\subsubsection{Health behaviour}

Physical activity: Three high-quality and one lowerquality studies considered the impact of physical activity on work disability. Duijts et al. [13] found that no leisure time physical activity was associated with risk of sick leave of three days or less (adjusted OR $=1.43$ ) and with sick leave of more than three days (crude OR $=1.32$ ) for individuals with psychosocial health complaints. O'Neil et al. [18] reported that decreased number of footsteps per day was associated with reduced work resumption after myocardial infarction. Kuijer et al. [25] found limited evidence that higher levels of physical activity were associated with a decrease risk of sickness absence at follow-up. Finally, the single lower quality rated review (van den Berg et al. [22]) reported strong evidence (4 out of 5 studies) that a lack of leisure time physical activity predicted poor work ability. There is strong evidence that decreased physical activity should be considered a predictor for work disability.

Sleep: Two high-quality systematic reviews considered the impact of sleep on work disability. Davey et al. [14] found that the presence of sleep problems was associated with increased risk of unplanned, short-term work absences in workers with mild illness or injury. Similarly, Kuijer et al. [25] reported that better sleep quality was associated with decreased risk of sickness absence at follow-up for individuals with low back pain. There is moderate evidence that sleep difficulties should be considered a predictor for work disability.

Substance use: Three systematic reviews were available regarding the use of alcohol, drugs and smoking; one high-quality, one moderate-quality, and one low-quality systematic review addressed the issue of substance use as a predictor for work disability. Duijts et al. [13] provided a high-quality rated review demonstrating that, for workers with mental health complaints, high levels of alcohol consumption was associated with increased risk of sick leave of over three days (adjusted OR $=1.24$ ). These authors also demonstrated that any level of smoking was associated with a decreased likelihood of return to work and that smoking behavior resulted in an additive interaction with overweight status. Likewise, in a moderatequality rated review, Blank et al. [16] found that smoking and/or any level of drug dependence was associated with a decreased likelihood of return to work for individuals with mental health conditions and, similar to Duijts et al. [13], their results suggested that smoking and drug use both demonstrated an additive interaction with overweight status. The final study, by van den Berg et al. [22], was a low-quality study that provided limited evidence that alcohol increased risk of poor WAI scores, regardless of health condition. There is moderate evidence that substance use should be considered a predictor for work disability.

\subsubsection{Non work time}

One high-quality and one low-quality systematic review considered the impact of time away from the workplace on work disability. Kuijer et al. [25], in a high-quality rated review, found that additional leisure time was associated with decreased risk of sick sickness absence at follow-up for individuals with low back pain. Fadyl et al. [27], in the single low-quality study, found that stronger routines outside of the workplace were associated with increased work ability for individuals with work-related injury. There is weak evidence that lack of or poorly planned non-work time should be considered a predictor for work disability. 
Table 4

Level of evidentiary support across systematic reviews

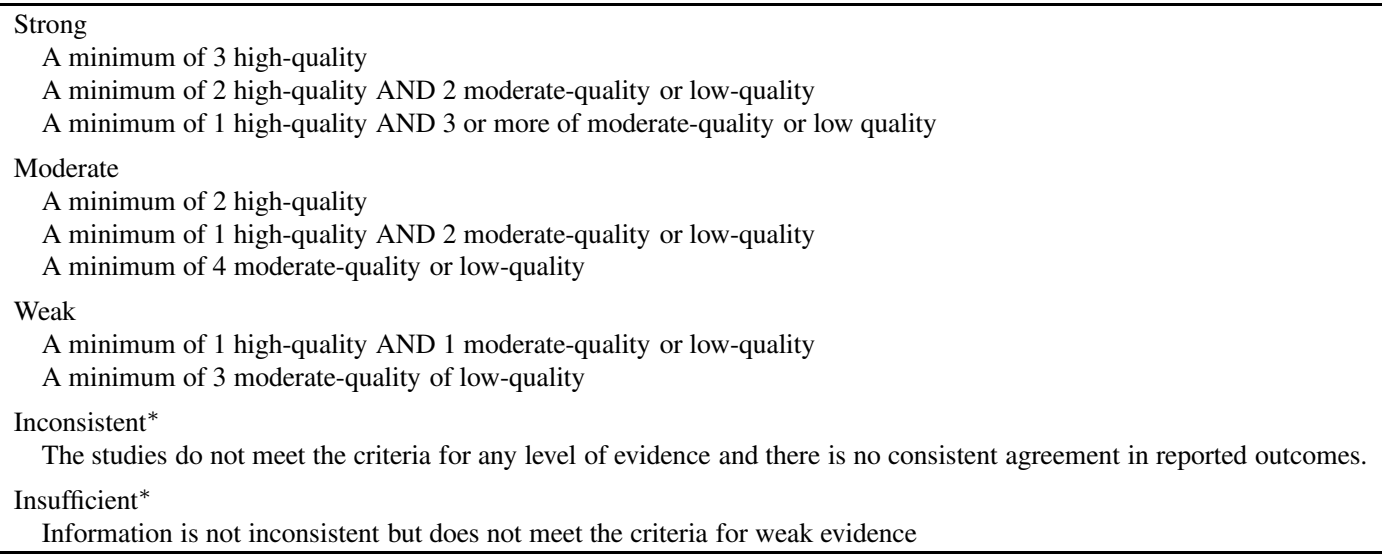

* The focus of this synthesis was the identification of risk factors, not the impact of interventions on work absence. Due to diversity of both clinical and occupational interventions and respective integrative conclusions, a summary statement cannot be made and thus evidence is labeled "inconsistent." However, factors identified in the included intervention studies may represent emerging or promising data for further investigation.

Table 5

Evidentiary support for modifiable worker factors

\begin{tabular}{|c|c|c|c|c|}
\hline Strong & Moderate & Weak & Inconsistent & Insufficient \\
\hline $\begin{array}{l}\text { Emotional distress and Increased } \\
\text { Depressive symptoms [13-19] }\end{array}$ & $\begin{array}{l}\text { Sleep difficulties } \\
{[14,25]}\end{array}$ & $\begin{array}{l}\text { Lack of, or poor planned, } \\
\text { non-work physical activity } \\
{[25,27]}\end{array}$ & & Fiber intake [22] \\
\hline $\begin{array}{l}\text { Negative enduring psychology/ } \\
\text { personality factors } \\
\text { (e.g., neuroticism) }[13,15,17,19-22]\end{array}$ & $\begin{array}{l}\text { Substance use } \\
{[13,16,22]}\end{array}$ & & & Experience of violence [13] \\
\hline $\begin{array}{l}\text { Negative health and disability } \\
\text { perception/negative recovery } \\
\text { expectations }[13,15,17-20,22-27]\end{array}$ & & & & Increased health concerns $[18]$ \\
\hline Decreased physical activity $[13,18,25]$ & & & & Psychosomatic health concerns [13] \\
\hline Lack of family support $[13,21,25-28]$ & & & & Absence duration [18] \\
\hline Poor general health $[14,17,18,24,29,30]$ & & & & Injury at work [16] \\
\hline $\begin{array}{l}\text { Increased functional disability factors } \\
{[17-19,24,25,29,31,32]}\end{array}$ & & & & Work unit separation [14] \\
\hline Increased pain $[17,19,20,25,26,32]$ & & & & Compassionate leave [14] \\
\hline Increased fatigue $[13,17,19,25]$ & & & & Lesser duration of employment $[17,36]$ \\
\hline \multirow{2}{*}{$\begin{array}{l}\text { Lack of motivation to return to work } \\
{[13,14,17,19,32,35]}\end{array}$} & & & & Transportation access [17] \\
\hline & & & & Positive role models $[17,36]$ \\
\hline
\end{tabular}

\subsubsection{Family support}

Family support: Three high-quality and three lowquality systematic reviews considered the impact of family support on work disability. Kuijer et al. [25], in one high-quality review, reported that more negative opinions or expectations from relatives about the illness/condition were associated with increased total number of sick leave days for workers with low back pain. A second high-quality review by Duijts et al. [13] found that, for individuals with psychosocial health complaints, low social support was associated with increased risk of sick leave of more than three days (crude OR $=1.22$ ). Cote and Coutu [21], in the final high-quality review in this area, found that greater domestic strain related to the injury/illness may negatively impact rehabilitation, especially for women with persistent musculoskeletal pain and increased family/home demands. Shaw et al. [26] provided a lowquality review with limited consistent evidence that increased domestic strain was associated with increased risk of longer disability for workers with low back pain. Spelten et al. [28] also provided a low-quality re- 
view that found increased mobilization of social support was associated with good return to work outcomes for individuals with cancer. Finally, Fadyl et al. [27] provided a low quality review that found better family support was associated with increased work ability for individuals with work-related injuries. There is strong evidence that a lack of family support should be considered a predictor for work disability.

\subsubsection{Health, psychosomatic and general health concerns}

General health level: Six systematic reviews considered the impact of general health level on work disability. A single moderate-quality review by Steenstra [29] reported strong evidence that poor general health level was associated with decreased likelihood of return to work for individuals with low back pain. Other evidence of this relationship was provided by four highquality reviews. Specifically, O'Neil et al. [18] found that reduced general health level was associated with reduced work resumption after myocardial infarction. Davey et al. [14] reported that general health level was associated with increased risk of unplanned, short-term work absences in individuals with mild injury or illness. Darr and Johns [30] found that physical illness was associated with increased risk of absenteeism in individuals with work stress. The final high-quality by review Hansson and Jensen [24] looking at this relationship found low evidence that more positive general health level was associated with decreased risk of sick leave of greater than three months. Lidal et al. [17], in a single low-quality review, also found that poor general health level was associated with decreased likelihood of return to work in individuals with spinal cord injury. There is strong evidence that poor general health level should be considered a predictor for work disability.

\subsubsection{Functional disability}

Seven systematic reviews considered the impact of disability factors on work disability. De Croon et al. [31] provided a high-quality review with strong evidence that additional activity limitations were associated with increased risk of work disability for individuals with rheumatoid arthritis. Detaille et al. [19] also provided a high-quality review with strong evidence that increased disability scores on the Health Assessment Questionnaire predicted increased risk of work disability for individuals with rheumatoid arthritis. Kuijer et al. [25] found limited evidence that for workers with non-specific chronic low back pain, low muscle endurance predicted increased number of days of work absence. Similarly, O'Neil et al. [18] provided a high quality report that physicians' perceptions of disability were associated with reduced work resumption after myocardial infarction. Steenstra et al. [29] in a single moderate-quality review considered this relationship and found strong evidence that disability at inception point predicted longer duration of sick leave (Pooled RR = 2.39). A low-quality review by Turner et al. [32] provided evidence of a similar relationship such that disability at inception was found to be associated with poor return to work outcomes for workers with work-related back injuries. Finally, Lidal et al. [17] provided a low-quality review suggesting that greater community mobility and independent living was associated with increased return to work rates for individuals with spinal cord injury. There is strong evidence that increased functional disability factors should be considered a predictor for work disability.

\subsubsection{Pain and fatigue}

Pain: Six systematic reviews considered the impact of pain on work disability. One high-quality review by Detaille et al. [19] found moderate level evidence suggesting that higher patient rating of pain was associated with increased risk of work disability for workers with rheumatoid. Other high-quality studies looking at this relationship included Truchon et al. [20] who found that persistent pain and/or difficulty coping with pain was associated with lack of return to work for individuals with low back pain. Kuijer et al. [25] reported limited evidence that pain in the cervical and thoracic region prior to injury was associated with increased risk of sickness absence at follow-up for individuals with low back pain. These authors also reported limited evidence that any bodily pain predicted increased number of days of work absence. Three lowquality systematic reviews also considered this relationship. Lidal et al. [17] found that increased neuropathic pain was associated with a decreased risk of return to work for workers with spinal cord injury; however, this relationship was found only in men. Turner et al. [32] reported that more severe pain, pain at more sites and increased pain related behaviors were associated with poorer return to work outcomes in individuals with work-related injury. Finally, Shaw et al. [26] found limited evidence that any bodily pain was associated with increased number of days of work absence for individuals with low back pain. There is strong evidence that pain should be considered a predictor for work disability.

Fatigue: Four systematic reviews considered the impact of fatigue on work disability. Three of these four 
reviews were deemed to be of high quality. Detaille et al. [19] reported moderate evidence that increased fatigue was associated with increased risk of work disability for individuals with rheumatoid arthritis. Duijts et al. [13] found that perpetual feelings of fatigue were associated with increased risk of sick leave over three days (adjusted OR $=1.32$ ) for individuals with psychosocial health concerns. Kuijer et al. [25] reported limited evidence that less fatigue at the end of the day was associated with decreased risk of sickness absence at follow-up for individuals with low back pain. In addition, Lidal et al. [17] provided a low-quality study that reported greater levels of fatigue as associated with decreased likelihood of return to work for individuals with spinal cord injury, especially in older workers. There is strong evidence that fatigue should be considered a predictor for work disability.

\subsubsection{Early clinical intervention approaches}

Six systematic reviews considered the impact of early interventions on factors believed to be predictive of work disability. Of the six available reviews, four were deemed to be of high quality. Nash et al. [33] provided strong evidence (13 of 14 studies) that use of early mobilization after acute limb injury was associated with an earlier return to work. Kuijer et al. [25] found that positive recommendations of rehabilitation by a team member were associated with decreased sickness absence at follow-up for individuals with low back pain. Dahm et al. [34] reported that use of bed rest as an intervention was predictive of longer sick leave for individuals with acute low back pain, whereas, staying active predicted reduced usage of sickness leave; however, interestingly, these authors also reported a reversed relationship among combat trainees (army). Detaille et al. [19] provided a high-quality review reporting weak evidence that for those with Rheumatoid Arthritis, less time to treatment was associated with a reduction of work disability. A moderatelevel review provided by Blank et al. [16] found that any attempt to return to work within 505 days of absence was associated with an increased likelihood of return to work in workers with stress in contrast to workers with mental illness or mental conditions there was a decreased likelihood of return to work. Turner et al. [32], in a single low-quality review, found weak evidence that less time to treatment was associated with poor return to work outcomes for workers with work-related back injuries. There is strong evidence that more time till intervention (or lack of recommendations for early movement) should be considered a predictor for work disability. However, there was contradictory evidence presented by Blank et al.'s [16] moderate-quality review with respect to workers with mental illness as well as by a low-quality review in situations of work-related back injuries. Therefore, this relationship should likely be considered dependent on type of injury.

\subsubsection{Work motivation}

Three high-quality reviews, one moderate-quality review, and three low-quality reviews considered the impact of work motivation on work disability. For thehigh-quality reviews, Davey et al. [14] found that higher job involvement was associated with reduced risk of unplanned, short-term work absences in workers with mild illness or injury. These authors also reported that higher commitment to the organization/workplace as well as personal accomplishment at work were both associated with reduced risk of unplanned short-term work absences. Duijts et al. [13] reported limited evidence that low level of functioning at work was associated with increased risk of poor work participation outcomes, including return to work and work status, for individuals with depression. The final high-quality review by Detaille et al. [19] found weak evidence that higher perceived importance of work, satisfaction with working conditions, and a desire to remain employed were associated with a reduced risk of work disability for individuals with rheumatoid arthritis. These authors also reported moderate evidence that a desire to remain employed was associated with reduced work disability in workers with ischemic heart disease. Michie et al. [35], in a single moderate-quality study, also considered this relationship and found that a lack of participation at work was associated with increased risk of sickness absence for individuals with psychological ill health. In addition, three low-quality studies considered this relationship. Specifically, Spelten et al. [28] found that changing attitudes towards work (in particular, reduced importance of work and decrease in aspirations related work) were associated with poor return to work outcomes for individuals with cancer. Turner et al. [32] found that a lack of confidence regarding ability to work in the future was associated with poorer return to work outcomes in individuals with work-related back injury. Finally, Lidal et al. [17] reported that positive attitudes towards work and achievement orientation were both associated with an increased return to work rate in individuals with spinal cord injury; similarly, these authors also reported that a lack of work motivation was associated 
with lesser return to work. There is strong evidence that a lack of work motivation should be considered a predictor for work disability.

\section{Discussions}

\subsection{Review of findings}

The present data consider the impact of modifiable worker variables on development of workplace disability. Psychological, physical and social support factors were found to have strong evidence for being considered as a predictor of disability across health conditions. Specifically, psychological factors including emotional distress and depression, psychological characteristics (e.g., locus of control, self-esteem), and health and disability perceptions (e.g., work ability, functional ability, hopefulness) have strong evidence for being considered a predictor of disability across health conditions. Additionally, lack of worker motivation was revealed as having strong evidence for being considered a risk factor to greater incidence of disability across health conditions. Generally, employees with more work commitment and desire to remain at work resulted in better reported return to work and stay at work outcomes. Physical factors with strong evidence for being considered predictors for work absence across health conditions included physical activity, general health and functional disability. Specifically, workers with greater reported rates of physical activity and better overall health were reported to have a lower risk of work-related disability; in contrast, increased issues with tasks of daily functioning (e.g., mobility) predicted poorer workplace outcomes. With respect to social support, only family support was considered in this current review; other forms of workplace-related support (e.g., supervisory support) are discussed in other reviews arising from the same project that assessed workplace, rather than workerrelated factors. For family support, strong evidence was found to suggest that high quality family support, with limited domestic strain, predicted better worker outcomes.

The final strong-evidence modifiable worker factor we considered to be related to each of psychological, physical and social support variables. That is, positive recommendations for early movement/return to work was seen as relating to workers' psychological interpretation of the disability event, but also impacting physical recovery and perceptions of social support for return to work. Consistent with the perceived complexity of this factor, the data suggested that recommendations for early movement are supported in the literature, but that these recommendations may vary across health conditions. That is, some evidence was available suggesting that early mobilization may not be helpful in all types of disability events.

In addition to the factors with strong evidence, our review found moderate evidence that substance use and sleep difficulties should be considered as predictors for disability. Specifically, for sleep only two high quality reviews were available substantially limiting the amount of interpretation possible from the available research. For substance use, three reviews were available; however, these reviews included one strong, one moderate and one low quality review limiting the overall strength of evidence. Additionally, limitation of interpretability for this factor was further hampered by diversity for the variable of interest (e.g., alcohol, drugs, smoking).

The present study found moderate to strong evidence for many modifiable worker variables that could contribute to unnecessary work absence and disability within the workplace. Consequently, employers may wish to consider these research-informed factors when considering workplace-supported interventions intended to improve employee health and well-being, and ultimately to reduce disability costs. However, interventions for worker variables may be futile if introduced in isolation or without consideration of current literature investigating successes and failures for workplace interventions directed at these factors.

\section{Implications and conclusion}

\subsection{Limitations}

Our first limitation was related to quality of original research; as is the case in all systematic review work, the quality of our review is limited by the quality of the primary source studies and the lack of consistency of functional and workplace outcome measures. Our second limitation was created through our choice of inclusion/exclusion criteria. That is, given our requirement that all included reviews be presented in the English language, we may have missed important and meaningful studies presented in other languages. Third, given the diversity of research designs and literature available for inclusion in this study, our analysis was limited to the weighing and reporting of findings 
based on methodological quality. Finally, this variability rendered us unable to determine the potential impact of any single or group of risk factor on work absences (i.e., overall estimate of variance-accounted-for effect size).

The academic community partnership provided a forum for researchers to better understand the information needs of end users and resulted in an active exchange that led to creation and refinement of the research question, and addressed a pragmatic need of small and medium sized employers who may not have the human resource capacity to consider individual worker risk or protective factors for a specific injury or chronic health condition. This best evidence synthesis will provide an opportunity to conduct a future synthesis on workplace interventions targeting these factors to provide research-evidence guidance on interventions to address factors relevant to their organization.

\section{Acknowledgments}

This paper is dedicated to Dr. Rick Iverson, who was a co-author on this manuscript. Dr. Iverson passed away suddenly on May 3, 2012 and participated in academic community stakeholder partnership meetings, search strategies, categorization of factors and the discussion section of this paper.

\section{References}

[1] Statistics Canada. Work Absence Rates. Ottawa, ON: Minister of Industry; 2011 May 1. Report No.: Catalogue no. 71-211$\mathrm{X}$.

[2] Health Canada. Economic Burden of Illness in Canada, 1998. Ottawa, ON: Minister of Public Works and Government Services Canada; 2002.

[3] Health Council of Canada. Why Health Care Renewal Matters: Learning from Canadians with Chronic Health Conditions. Toronto, ON: Health Council of Canada; 2007 Jan 12.

[4] White MI, Kube D, Petruniak J et al. Best Practices Leadership Summit on Disability Prevention. Vancouver, BC: Canadian Institute for the Relief of Pain and Disability; 2007.

[5] White M, Wagner S, Schultz IZ et al. Modifiable workplace risk factors contributing to workplace absence across health conditions: A stakeholder-centered best-evidence synthesis of systematic reviews. Work 2013.

[6] Finding What Works in Health Care: Standards for Systematic Reviews. Washington, DC: Institute of Medicine of the National Academies; 2011.

[7] Shea BJ, Grimshaw JM, Wells GA et al. Development of AMSTAR: a measurement tool to assess the methodological quality of systematic reviews. BMC Med Res Methodol 2007; 7 : 10 .
[8] Slavin RE. Best evidence synthesis: an intelligent alternative to meta-analysis. J Clin Epidemiol 1995; 48(1): 9-18.

[9] Carroll LJ, Cassidy JD, Peloso PM et al. Methods for the best evidence synthesis on neck pain and its associated disorders: the Bone and Joint Decade 2000-2010 Task Force on Neck Pain and Its Associated Disorders. Spine (Phila Pa 1976) 2008; 33(4 Suppl): S33-S38.

[10] Franche RL, Cullen K, Clarke J, Irvin E, Sinclair S, Frank J. Workplace-based return-to-work interventions: a systematic review of the quantitative literature. J Occup Rehabil 2005; 15(4): 607-631.

[11] VonVille H. Excel workbookto track systematic review search results. 2011. Houston, Texas, The University of Texas School of Public Health. Ref Type: Online Source.

[12] Moher D, Liberati A, Tetzlaff J, Altman DG. Preferred reporting items for systematic reviews and meta-analyses: the PRISMA statement. J Clin Epidemiol 2009; 62(10): 10061012.

[13] Duijts SF, Kant I, Swaen GM, van den Brandt PA, Zeegers MP. A meta-analysis of observational studies identifies predictors of sickness absence. J Clin Epidemiol 2007; 60(11): 1105-1115.

[14] Davey MM, Cummings G, Newburn-Cook CV, Lo EA. Predictors of nurse absenteeism in hospitals: a systematic review. J Nurs Manag 2009; 17(3): 312-330.

[15] Lagerveld SE, Bultmann U, Franche RL et al. Factors associated with work participation and work functioning in depressed workers: a systematic review. J Occup Rehabil 2010; 20(3): 275-292.

[16] Blank L, Peters J, Pickvance S, Wilford J, Macdonald E. A systematic review of the factors which predict return to work for people suffering episodes of poor mental health. J Occup Rehabil 2008; 18(1): 27-34.

[17] Lidal IB, Huynh TK, Biering-Sorensen F. Return to work following spinal cord injury: a review. Disabil Rehabil 2007; 29(17): 1341-1375

[18] O’Neil A, Sanderson K, Oldenburg B. Depression as a predictor of work resumption following myocardial infarction (MI): a review of recent research evidence. Health Qual Life Outcomes 2010; 8: 95.

[19] Detaille SI, Heerkens YF, Engels JA, van der Gulden JW, van Dijk FJ. Common prognostic factors of work disability among employees with a chronic somatic disease: a systematic review of cohort studies. Scand J Work Environ Health 2009; 35(4): 261-281.

[20] Truchon M, Fillion L. Biopsychosocial determinants of chronic disability and low-back pain: a review. J Occup Rehabil 2000; 10(2): 117-142.

[21] Cote D, Coutu MF. A critical review of gender issues in understanding prolonged disability related to musculoskeletal pain: how are they relevant to rehabilitation? Disabil Rehabil 2010; 32(2): 87-102.

[22] van den Berg TI, Elders LA, de Zwart BC, Burdorf A. The effects of work-related and individual factors on the Work Ability Index: a systematic review. Occup Environ Med 2009; 66(4): 211-220.

[23] Iles RA, Davidson M, Taylor NF. Psychosocial predictors of failure to return to work in non-chronic non-specific low back pain: a systematic review. Occup Environ Med 2008; 65(8): 507-517.

[24] Hansson T, Jensen I. Swedish Council on Technology Assessment in Health Care (SBU). Chapter 6. Sickness absence due to back and neck disorders. Scand J Public Health Suppl 2004; 63: 109-151. 
[25] Kuijer W, Groothoff JW, Brouwer S, Geertzen JH, Dijkstra PU. Prediction of sickness absence in patients with chronic low back pain: a systematic review. J Occup Rehabil 2006; 16(3): 439-467.

[26] Shaw WS, Pransky G, Fitzgerald TE. Early prognosis for low back disability: intervention strategies for health care providers. Disabil Rehabil 2001; 23(18): 815-828.

[27] Fadyl JK, McPherson KM, Schluter PJ, Turner-Stokes L. Factors contributing to work-ability for injured workers: literature review and comparison with available measures. Disabil Rehabil 2010; 32(14): 1173-1183.

[28] Spelten ER, Sprangers MA, Verbeek JH. Factors reported to influence the return to work of cancer survivors: a literature review. Psychooncology 2002; 11(2): 124-131.

[29] Steenstra IA, Verbeek JH, Heymans MW, Bongers PM. Prognostic factors for duration of sick leave in patients sick listed with acute low back pain: a systematic review of the literature. Occup Environ Med 2005; 62(12): 851-860.

[30] Darr W, Johns G. Work strain, health, and absenteeism: a meta-analysis. J Occup Health Psychol 2008; 13(4): 293-318.

[31] De Croon EM, Sluiter JK, Nijssen TF, Dijkmans BA,
Lankhorst GJ, Frings-Dresen MH. Predictive factors of work disability in rheumatoid arthritis: a systematic literature review. Ann Rheum Dis 2004; 63(11): 1362-1367.

[32] Turner JA, Franklin G, Turk DC. Predictors of chronic disability in injured workers: a systematic literature synthesis. Am J Ind Med 2000; 38(6): 707-722.

[33] Nash CE, Mickan SM, Del Mar CB, Glasziou PP. Resting injured limbs delays recovery: a systematic review. J Fam Pract 2004; 53(9): 706-712.

[34] Dahm KT, Brurberg KG, Jamtvedt G, Hagen KB. Advice to rest in bed versus advice to stay active for acute low-back pain and sciatica. Cochrane Database Syst Rev 2010; 6(6): CD007612.

[35] Michie S, Williams S. Reducing work related psychological ill health and sickness absence: a systematic literature review. Occup Environ Med 2003; 60(1): 3-9.

[36] Peters J, Pickvance S, Wilford J, Macdonald E, Blank L. Predictors of delayed return to work or job loss with respiratory ill-health: a systematic review. J Occup Rehabil 2007; 17(2): 317-326. 